\title{
A CONCEPÇÃO HOLÍSTICA E PROCESSUAL DE TEMPO DE NORBERT ELIAS ${ }^{1}$
}

\author{
Eugênio Rezende de Carvalho
}

é Professor Titular da Faculdade de História da Universidade Federal de Goiás. Goiânia, GO, Brasil.

E-mail: <eugeniodecarvalho@gmail.com>

http://dx.doi.org/10.1590/0102-203231/103

... o tempo é um tecido invisível em que se pode bordar tudo, uma flor, um pássaro, uma dama, um castelo, um túmulo. Também se pode bordar nada. Nada em cima de invisível é a mais sutil obra deste mundo, e acaso do outro.

Machado de Assis, Esaú e Jacó

De acordo com as reflexões sobre o tempo do sociólogo alemão Norbert Elias (1897-1990), as tradições filosóficas do objetivismo e do subjetivismo e as teorias tradicionais do conhecimento - que tendiam a conceber o mundo a partir de uma infinitude de antíteses não processuais - seriam responsáveis pelas divisões conceituais dicotômicas entre objeto e sujeito, natureza e sociedade, mundo físico e social, tempo objetivo e subjetivo, tempo físico e social, tempo da natureza e da consciência, tempo cosmológico e fenomenológico etc. como partes existencialmente independentes e inconciliáveis. Por isso, o esforço teórico de Elias se concentrou em elaborar uma síntese processual para o problema do tempo que refutasse dualismos

\footnotetext{
1 A investigação que resultou na presente publicação recebeu o apoio do Conselho Nacional de Desenvolvimento Científico e Tecnológico (CNPq).
} 
e conectasse numa unidade pares dicotômicos - não apenas como uma mera soma, mas como uma articulação necessária -, apoiando-se no reconhecimento da interdependência e imbricação mútua entre os níveis físico, biológico, social e individual, sem o qual - para Elias - o enigma que envolve o conceito de tempo continuaria sem solução.

As bases teórico-filosóficas - e, destacadamente, epistemológicas - da investigação de Elias sobre o tempo podem ser buscadas principalmente em seus clássicos $O$ processo civilizador $^{2}$ (2011, 1993) - especialmente o primeiro volume, publicado originalmente em 1939 - e A sociedade dos indivíduos (1994a) - as duas primeiras partes, escritas em décadas anteriores à publicação do livro em 1987 -; assim como em Envolvimento e alienação (1998a), em suas entrevistas e notas biográficas (1994b, 2001) - publicadas pela primeira vez em 1984 e posteriormente reunidas e transformadas em livro e, sobretudo, em The symbol theory ${ }^{3}$ (Teoria do simbolo, 1991), o 204 último livro publicado por Elias antes de sua morte. As referências de Elias - diretas ou indiretas - à problemática conceitual do tempo foram raras em suas primeiras obras e um pouco mais frequentes em seus últimos estudos. Todavia, indubitavelmente, a mais importante fonte de investigação do conceito de tempo de Norbert Elias é constituída basicamente de uma série de ensaios reunidos e publicados em 1984 no livro Über die zeit (Sobre o tempo). ${ }^{4}$ É com a

2 Elias estabeleceu alguns vínculos importantes entre seu estudo sobre o tempo e investigações anteriores sobre o processo de civilização, notadamente no que se refere ao sentido das mudanças no uso do tempo, tanto na esfera social quanto na dimensão física do universo, como meio de orientação e de regulação da conduta humana. Ver, a propósito, Elias e Dunning (1992, p. 44).

3 Obra sem tradução para o português. Utilizamos, neste artigo, a tradução espanhola (Elias, 1994c).

4 A primeira parte dos manuscritos desses ensaios foi redigida em inglês e publicada em holandês na revista De gids, entre 1974 e 1975, sendo que o restante foi escrito diretamente em alemão, quando da publicação em forma de livro, em 1984, de todo o conjunto desses 46 ensaios apenas numerados - incluindo a tradução para o alemão da primeira parte. Utilizamos neste artigo a edição brasileira (Elias, 1998b). 
publicação desse livro que Elias entraria definitivamente no debate filosófico sobre o caráter do tempo.

Conquanto esse tenha sido um assunto de certa forma marginal quando comparado a tantas outras temáticas que integraram sua teoria sociológica mais geral, as reflexões de Elias sobre o tempo alcançaram nas últimas décadas uma grande difusão e repercussão, tornando-se leitura obrigatória para quem quer que se proponha ao estudo do tema. A importância maior de sua contribuição ao debate acerca da natureza do tempo reside principalmente em sua visão holística e processual do fenômeno temporal, uma visão que busca não apenas se afastar da dicotomia entre as abordagens objetivistas e subjetivistas, mas superá-la, de forma a melhor compreender e elucidar o problema filosófico, epistemológico, social e histórico do tempo.

\section{O tempo como um símbolo social, uma síntese conceitual de alto nível}

Em seu esforço de propor uma compreensão do tempo que abrisse caminho entre as alternativas filosóficas tradicionais do subjetivismo e do objetivismo, do nominalismo e do realismo, Elias deixou clara a necessidade, para tanto, de fornecer "elementos de interpretação dos símbolos sociais". Nesse sentido, seu estudo acerca do tempo integrou uma investigação mais ampla - em parte realizada posteriormente à publicação de seu livro Sobre o tempo - que visou à elaboração de uma teoria geral do símbolo, já que para ele o tempo seria um símbolo relacional e socialmente comunicável (Elias, 1998b, p. 27). Assim, a investigação de Elias sobre o tempo, nas décadas de 1970 e 1980, motivou-o a desenvolver uma teoria mais geral a respeito dos símbolos, o que resultou na elaboração e publicação, em 1989, do seu livro The symbol theory, uma fonte fundamental para compreender sua abordagem do tempo. Junto a outras obras como Sobre o tempo e Envolvimento e alienação - publicados originalmente em 1984 e 1983, respectivamente -, esse livro integra o que poderíamos chamar 
de grupo de escritos eliasianos sobre sociologia do conhecimento, nos quais ele incorpora certos fundamentos - embora não todos - da sociologia do conhecimento do húngaro Karl Mannheim (1893-1947), de quem foi amigo e colaborador.

Em Teoria do símbolo, Elias se propôs a detalhar sua teoria, a qual visaria, em síntese, colocar e resolver a questão da natureza do conhecimento em sua conexão indissolúvel com a linguagem e o pensamento (Elias, 1994c, p. 171). Nota-se nesse livro uma convergência significativa das teses de Elias com as ideias a respeito dos símbolos formuladas pelo filósofo Ernst Cassirer em Filosofia das formas simbólicas (2001, 2004, 2011) e pelo semiólogo Umberto Eco em Semiótica e filosofia da linguagem (1991) - o que é corroborado na obra por meio das referências explícitas a esses autores. Aliás, foi Cassirer quem mais tarde afirmou que antes de se definir o homem como um animal racional, ele deveria ser definido como animal symbolicum (Cassirer, 1994, p. 50). Ao ressaltar o caráter 206 simbólico do tempo, Elias lembrou, antes de tudo, que os símbolos sociais são a forma dominante de comunicação humana, e que os homens se inserem num mundo de símbolos que eles mesmos criaram e dos quais são dependentes.

$\mathrm{O}$ fato de os homens deverem e poderem se orientar em seu mundo adquirindo um saber, e de, com isso, sua vida individual e coletiva depender totalmente da aprendizagem de símbolos sociais, é uma das particularidades que diferenciam o ser humano de todos os outros seres vivos. Ora, o tempo faz parte dos símbolos que os homens são capazes de aprender e com os quais, em certa etapa da evolução da sociedade, são obrigados a se familiarizar, como meios de orientação (Elias, 1998b, p. 20).

Segundo Elias, os instrumentos de medição do tempo, por exemplo, seja qual for a sua natureza, sempre nos transmitem mensagens. De modo que, quando afirmamos que 
os instrumentos de mensuração do tempo - como os relógios - indicam o "tempo", isso significaria que eles o fazem por meio de uma emissão de mensagens, de uma produção contínua de símbolos, que funcionam como meios de orientação. Para que um processo físico se convertesse num instrumento de determinação do tempo, seria necessário que ele se associasse a um símbolo social móvel, sob a forma de informação ou regulação, inserido no sistema de comunicação das sociedades humanas. Isso não significa, entretanto, que poderíamos simplesmente separar a dimensão simbólica de um instrumento de mensuração do tempo de suas propriedades físicas. Para Elias, o tempo enquanto símbolo não seria inconciliável com o seu caráter de dimensão do universo físico (Elias, 1998b, p. 16). Dessa maneira,

as configurações móveis que servem para a determinação temporal dos acontecimentos são transformadas pelos habitus sociais dos espectadores em representações simbólicas de momentos puros do escoamento de um "tempo imaterial". E este, segundo a expressão consagrada, parece "seguir seu curso”, independentemente de qualquer movimento físico e qualquer testemunho humano (Elias, 1998b, p. 97).

Daí o tempo ter se tornado, paulatinamente, uma representação simbólica de uma ampla rede de relações, que envolvem processos variados. Mas seria necessária uma ação humana ordenadora, uma "síntese conscientemente aprendida", para que tais processos fossem captados no espaço e no tempo. Diante disto, de acordo com Elias, a noção de tempo representaria, em seu estágio atual de desenvolvimento, uma síntese conceitual de altíssimo nível, ${ }^{5}$

\footnotetext{
5 Elias preferiu a expressão "sínteses de alto nível" ao emprego do termo mais costumeiro, "abstrações", por considerar a "falta de clareza" desse último, tal como ocorre na polaridade conceitual "abstrato-concreto", que lhe seria aparentada. Ver Elias (1998b, p. 138).
} 
exatamente por relacionar posições ou durações, seja no desenrolar dos eventos físicos, na dinâmica social ou mesmo no curso de uma vida individual (Elias, 1998b, p. 17). Em consonância com tal abordagem, a percepção do tempo exigiria seres dotados de um poder de síntese - uma particularidade da espécie humana -, acionado e estruturado pela experiência individual e coletiva, capaz de elaborar uma imagem mental que reunisse, numa única representação, eventos sucessivos não simultâneos:

para se orientar, os homens servem-se menos do que qualquer outra espécie de reações inatas e, mais do que qualquer outra, utilizam percepções marcadas pela aprendizagem e pela experiência prévia, tanto a dos indivíduos quanto a acumulada pelo longo suceder das gerações (Elias, 1998b, p. 33). ${ }^{6}$

Por essa razão, em conformidade com a teoria sociológica configuracional, processual e de longo prazo de Norbert Elias - tradicionalmente designada de sociologia evolutiva (Elias, 1994c, p. 60 e 68) ${ }^{7}$-, os símbolos que pressupõem um alto nível de generalização e síntese, como é o caso do tempo, por serem resultantes de um longo processo social de aprendizagem e experiência, pertenceriam a um estágio relativamente avançado na evolução não apenas dos símbolos humanos, mas das instituições sociais correspondentes (Elias, 1998b, p. 108). Daí o conceito atual de tempo

\footnotetext{
6 Aqui Elias contrapõe o adquirido, o aprendido pela experiência, ao inato, embora se possa dizer que tal contraposição não é absoluta, na medida em que o inato e o adquirido de certa forma andam juntos. Se for verdade, por exemplo, que a capacidade de linguagem é inata e que toda língua é aprendida, deve haver algum tipo de articulação entre ambas.

7 Embora Elias tenha estabelecido a distinção entre os termos evolução e desenvolvimento, limitando o primeiro ao significado de símbolo dos processos biológicos de transmissão genética, e o segundo aos processos humanos não evolutivos de transmissão simbólica intergeracional em suas diversas formas.
} 
requerer um vasto patrimônio social de saber acumulado, construído e transmitido - eventualmente aperfeiçoado ao longo de gerações, o que se torna mais claro quando o contrastamos com as noções de tempo utilizadas por nossos ancestrais ou pelos indivíduos de formações sociais mais simples. Um dos problemas das epistemologias tradicionais, segundo Elias, seria exatamente que a maioria delas pouco diz sobre a transmissão de conhecimento de pessoa a pessoa, e praticamente nada a respeito da transmissão de conhecimento entre gerações (Elias, 1994c, p. 137). Em Sobre o tempo, podemos encontrar uma demonstração, recheada de exemplos, do processo de desenvolvimento - e não progresso - da percepção humana do tempo ao longo da história; do processo de como o conceito de tempo, com o passar dos séculos, foi se modificando através das distintas civilizações até atingir o grau de complexidade que o caracteriza nas sociedades contemporâneas.

\section{Alguns problemas decorrentes do caráter simbólico do tempo}

Ao ressaltar o caráter enigmático que reveste nossa noção cotidiana do tempo, Elias afirmou que o seu estatuto ontológico permanecia obscuro: "O tempo é um objeto natural, um aspecto dos processos naturais, um objeto cultural? $\mathrm{Ou}$ será em virtude de o designarmos por um substantivo que nos iludimos com seu caráter de objeto?” (Elias, 1998b, p. 14). Cumpre em seguida refletir sobre alguns aspectos que, segundo nosso autor, contribuiriam para reforçar e manter esse aparente mistério em torno do caráter do tempo.

Ao analisar a antítese filosófica sobre a essência do tempo, Elias ressaltou que as duas posições antagônicas objetivista e subjetivista - acabavam por apresentá-lo como um dado natural. Muitas das confusões e embaraços à compreensão do tempo teriam origem precisamente nessa tendência à sua naturalização, ou seja, à naturalização de algo 
que, enquanto uma síntese conceitual e um símbolo social, não é natural, no sentido de independente dos seres humanos e de suas experiências com os outros homens e com o mundo não humano. Assim, segundo tal perspectiva, o enigma que envolve a ideia de tempo decorreria em grande parte do seu caráter simbólico e, consequentemente, das questões ligadas à própria linguagem. Conforme pensava Elias, grande parte do problema residiria no fato de empregarmos cotidianamente o termo tempo como substantivo, em lugar de verbo, o que acaba contribuindo para a sua reificação.

Inúmeras locuções familiares sugerem que o tempo seria um objeto físico. Já o simples fato de evocar a ação de "medir" o tempo parece assemelhá-lo a um objeto físico mensurável, como uma montanha ou um rio. A expressão "no correr do tempo" parece implicar que os homens, e talvez o universo inteiro, flutuariam no tempo como num rio. Neste e em muitos outros casos, a forma substantiva que se dá à noção de tempo contribui muito, com certeza, para criar a ilusão de que ele seria uma espécie de coisa "no espaço-tempo" (Elias, 1998b, p. 39).

A reflexão sobre a questão do tempo ficaria assim dificultada exatamente pela forma substantiva de que se revestiria esse conceito. A prática de se pensar e falar com o auxílio de substantivos reificadores, de personificar abstrações, para Elias, era uma convenção que restringia imensamente a percepção dos nexos entre os acontecimentos. É o caso, por exemplo, de quando se utiliza expressões do tipo “o vento sopra”: mas não seria o vento a própria ação de soprar? Acaso há um vento que não sopre? O mesmo ocorreria com o conceito de tempo, quando dizemos que ele "passa", quando em realidade o que "passa", ou o que flui, são os processos específicos e tangíveis, sejam eles individuais, sociais ou naturais. Tais hábitos linguísticos de 
substantivação contribuiriam assim para distorcer a reflexão, fortalecendo "o mito do tempo como uma coisa de certo modo presente, existente e, como tal, determinável e mensurável pelo homem, ainda que não se deixe perceber pelos sentidos". Desse modo, tal problema se ligaria em grande parte à natureza simbólica do tempo. Como os símbolos temporais, de modo análogo aos símbolos matemáticos, poderiam servir para relacionar sequências bastante diversas, teria se criado a falsa impressão de que o "tempo" existe, ou de que pudesse existir, independentemente de qualquer uma dessas sequências específicas e tangíveis. E quanto mais complexa e diferenciada a sociedade, maior seria tal impressão (Elias, 1998b, pp. 37-38 e 84).

Outra dificuldade derivada do fato de o tempo ser uma relação entre processos muito variados é que se cria uma tendência a atribuir-lhe algumas propriedades desses mesmos processos. Esse seria um exemplo da maneira como um símbolo largamente empregado, como uma síntese conceitual de altíssimo nível, poderia, a partir da sua desvinculação dos processos que ele compara, adquirir autonomia na linguagem e no pensamento humano, alcançando, por vezes, o status de uma segunda natureza. ${ }^{8} \mathrm{Ou}$ um exemplo de como, num universo socio-simbólico como o nosso, é habitual "a linguagem corrente reificar os símbolos mais abstratos e lhes conferir vida própria”. E mais, quando tais símbolos chegam a alcançar um elevado grau de adequação à realidade - como é o caso do tempo, nas configurações sociais mais complexas da atualidade -, seria cada vez mais frequente, conforme Elias, os homens os confundirem com a própria realidade (Elias, 1998b, p. 11, 57 e 97).

\footnotetext{
8 Em seu livro Introdução à sociologia, publicado originalmente em 1970, Elias explorou mais detalhadamente esse tema ao abordar a pressão social das estruturas verbais e conceituais, que atuam por vezes como entidades ou forças extra-humanas exercidas sobre as pessoas, como se fossem “objetos". Ver Elias (2008, p. 21)
} 


\section{O tempo como um símbolo puramente relacional}

Além de se constituir num símbolo social comunicável, uma síntese conceitual de alto nível, aquilo a que chamamos tempo se configuraria ainda, para Elias, como uma espécie de relação, evidentemente que de cunho social e simbólico. Nesse sentido, a palavra tempo designaria simbolicamente

a relação que um grupo humano, ou qualquer grupo de seres vivos dotado de uma capacidade biológica de memória e de síntese, estabelece entre dois ou mais processos, um dos quais é padronizado para servir aos outros como quadro de referência e padrão de medida (Elias, 1998b, pp. 39-40).

Essa concepção de tempo como uma relação ou comparação teve uma de suas principais formulações em Espinosa, quem afirmou: "para determinar a duração nós a comparamos com a duração daquelas coisas que possuem um 212 movimento certo e determinado. Esta comparação chama-se tempo" (Espinosa, 1983, p. 12). Nessa perspectiva, num hipotético universo "monódromo", ou seja, que comportasse uma única sequência de mudanças, não teria qualquer sentido a pergunta sobre quando aconteceu algo, ante a ausência de uma segunda sequência de mudanças a partir da qual se pudesse estabelecer a relação - a não ser que a referência fosse intrínseca ou interna à própria sequência. Analogamente, não poderíamos falar de tempo num universo em que tudo ficasse imóvel, ou em que as sequências de mudanças não apresentassem uma estrutura contínua, independente de suas diferenças de natureza (Elias, 1998b, pp. 59-60).

Assim, sendo o tempo uma relação, seria mais vantajoso, para sua melhor compreensão, conforme a sugestão de Elias, se pudéssemos modificar os hábitos linguísticos e transformar o substantivo "tempo" em um verbo - em algo como "temporalizar" -, pois na realidade se trataria disso: de uma ação que visaria ao estabelecimento de comparações 
entre posições ou durações; mais do que uma relação, seria o ato de colocar em relação - nesse sentido, uma ação de sincronizar. Assim, o enfoque eliasiano considera que esse ato de relacionar diferentes durações exigiria a presença de, no mínimo, três elementos: os sujeitos humanos, autores da relação, além de duas ou mais durações, entre as quais uma funcionaria como padrão de referência. ${ }^{9} \mathrm{Ou}$ seja, desses elementos depende o conceito ou significado de tempo. É relevante observar aqui que tal caráter relacional do tempo também se aplicaria ao espaço, com a diferença de que no caso do tempo os padrões de medida seriam móveis, enquanto no caso do espaço os padrões de medida seriam estáticos. Gottfried W. Leibniz (1646-1716) havia afirmado que o espaço e o tempo eram relativos - ao contrário da perspectiva absolutista de seu contemporâneo inglês, o físico Isaac Newton (1643-1727). Para o filósofo e cientista alemão, "o espaço é algo puramente relativo, como o tempo; a saber, na ordem das coexistências, como o tempo na ordem das sucessões" (Leibniz, 1983, p. 177).

Diante da impossibilidade de se confrontar diretamente a duração de sequências que se desenrolam uma após outra e visando a atender suas necessidades de orientação, os seres humanos teriam lançado mão, historicamente, de uma segunda sucessão de processos para comparar as suas durações de forma indireta - processos esses socialmente padronizados e regulares, como os ciclos do movimento aparente do Sol ou do ponteiro de um relógio (Elias, 1998b, p. 13).

Portanto, o que chamamos "tempo" significa, antes de mais nada, um quadro de referência do qual um grupo humano mais tarde, a humanidade inteira — se serve para erigir,

\footnotetext{
9 Como bem lembrou nosso autor, coube a Einstein reforçar ainda mais esse caráter relacional do tempo ao colocá-lo como dependente do ponto de referência do observador, revisando assim toda a noção newtoniana do tempo como um fluxo objetivo e absoluto. Ver Elias (1998b, p. 38).
} 
em meio a uma sequência contínua de mudanças, limites reconhecidos pelo grupo, ou então para comparar uma certa fase, num dado fluxo de acontecimentos, com fases pertencentes a outros fluxos, ou ainda para muitas outras coisas (Elias, 1998b, p. 60).

Em síntese, Elias qualificou o tempo, entre outros aspectos, como um símbolo puramente relacional, da mesma categoria dos símbolos matemáticos, no sentido de que as relações que ele representa simbolicamente não remetem a um ou outro objeto ou acontecimento particular. ${ }^{10}$ Assim concebido, esse conceito de tempo pôde ser aplicado a contínuos evolutivos de qualquer espécie - do cozimento de um ovo ao nascimento e desaparecimento das estrelas e galáxias -, bastando apenas que houvesse a padronização social de uma sequência que funcionasse como modelo, fosse ela de ordem física ou social (Elias, 1998b, p. 107).

\section{A distinção entre conceitos temporais "estruturais" $e$ "experienciais"}

$\mathrm{Na}$ abordagem eliasiana, o tempo designaria simbolicamente uma relação, uma comparação indireta estabelecida por um grupo humano entre posições ou intervalos de duração de uma determinada sequência evolutiva e regular de mudanças - recorrente ou não -, tomada como referencial, e outras posições ou intervalos de duração de outra(s) sequência(s) de acontecimentos, sejam elas naturais, biológicas, sociais ou pessoais. Exemplos de sequências evolutivas de mudanças, regulares e socialmente padronizadas - nesse caso também recorrentes -, seriam os ciclos do movimento

\footnotetext{
10 A título de exemplo, o símbolo representado pelo algarismo quatro, por si só, não significa nada caso não seja relacionado a um objeto específico, como em "quatro maçãs". Justamente por essa razão os símbolos matemáticos podem ser aplicados a inúmeros objetos diferentes, analogamente ao símbolo do tempo. Ver Elias (1998b, p. 107).
} 
aparente do Sol ou da Lua em torno da Terra, origem das unidades padrão de medida ano e mês, respectivamente; ou ainda os ciclos do ponteiro de um relógio, que nos dão a unidade de medida hora. Mas o tempo poderia designar também, além de comparações indiretas entre posições ou intervalos de duração de diferentes processos, relações no âmbito de uma única e mesma sequência de eventos, entre o que ocorreu "mais cedo" e o que ocorreu "mais tarde", entre o "antes" e o "depois". Evidentemente que, nesse caso, o ponto de referência situar-se-ia no interior da mesma sequência evolutiva (Elias, 1998b, p. 61). Daí

uma das chaves essenciais para resolver os problemas suscitados pelo tempo e por sua determinação é a capacidade, característica da espécie humana, de apreender num relance e, por isso mesmo, ligar numa mesma sequência contínua de acontecimentos aquilo que sucede "mais cedo" e o que sucede "mais tarde", o "antes" e o "depois". A memória desempenha um papel decisivo nesse tipo de representação, que enxerga em conjunto aquilo que não se produz num mesmo momento (Elias, 1998b, p. 61).

Tal capacidade de síntese, de ligar o "antes" e o "depois" numa mesma sequência de eventos, expressaria a habilidade dos homens de presentificar para si o ausente e ligá-lo ao que se encontra efetivamente presente - é essa possibilidade de referência de algo presente a algo não presente que normalmente caracteriza a noção de signo que, em seu sentido convencional (caso dos símbolos matemáticos), seria sinônimo de símbolo. Os conceitos de antes e depois traduziriam, nesse caso, "a capacidade humana de abarcar numa só representação acontecimentos que não ocorrem ao mesmo tempo, e que tampouco são experimentados como simultâneos". Elias destaca, por exemplo, que não haveria sentido na afirmação "são quatro horas", sem a consciência 
simultânea de que antes "eram duas horas" e, depois, "serão seis" (Elias, 1998b, pp. 61-62). Assim, o problema do tempo representaria uma complexa relação instrumental

entre sequências de acontecimentos, a qual é estabelecida, com certos objetivos, por grupos humanos mais ou menos solidamente organizados, entre ou dentro de contínuos evolutivos observáveis, podendo essa operação incluir ou não o continuum constituído por esses próprios grupos (Elias, 1998b, p. 62).

Acrescentaríamos, seguindo a perspectiva do autor: podendo incluir ou não a capacidade humana de elaborar sínteses conceituais, bem como podendo incluir ou não a dimensão da experiência vivida. Nesse ponto, pode-se inferir da análise de Norbert Elias que a existência de inúmeras e diferentes expressões temporais criadas e empregadas pelos 216 homens - tais como "ano", "mês", "hora", "antes", "depois", "mais cedo", "mais tarde”, "agora”, "hoje”, "passado", "presente", "futuro" etc. - decorreria, entre outros aspectos, do fato de considerarmos as relações entre ou dentro de contínuos observáveis, de incluirmos ou não, na elaboração dessa conceituação, a capacidade humana de efetuar sínteses e, sobretudo, a experiência vivida pelos homens.

Segundo Elias, em razão da falta de clareza sobre aquilo que os diferenciaria e aquilo que os aproximaria, a função e a significação desses conceitos temporais permaneciam mal-entendidas (Elias, 1998b, p. 62). Com o propósito de melhor esclarecê-las, ele relacionou, num primeiro momento, os conceitos mais simples, de caráter serial, tais como ano, mês e hora, com os mais complexos, de passado, presente e futuro:

Enquanto os conceitos pertencentes à primeira categoria representam a estrutura temporal da sequência de acontecimentos como tal, o conteúdo de significação dos da 
segunda inclui a atividade humana de síntese que considera essas sequências e sua estrutura temporal. O enigma que eles [conceitos de passado, presente e futuro] colocam diante de nossa inteligência repousa, acima de tudo, no caráter oscilante de sua ordenação da estrutura temporal das sequências: o futuro de hoje é o presente de amanhã, e o presente de hoje é o passado de amanhã (Elias, 1998b, p. 62).

Para solucionar tal enigma, Elias sustentou que bastaria lembrar o modo específico de ligação encontrado nos estudos da experiência humana, tomando em conta o aparelho categorial exigido para a representação simbólica de tal experiência: notar-se-ia que "passado", "presente" e "futuro" designariam os conceitos necessários para a representação desse modo de ligação. A significação desses conceitos encontrar-se-ia em constante evolução, em razão de que "os próprios homens a quem esses conceitos remetem e dos quais eles traduzem a experiência estão em constante evolução". Nessa perspectiva, conceitos como "ano", "mês" ou "hora" não integrariam a aptidão humana de vivenciar como simultaneidade o que não ocorre na simultaneidade, ainda que pudessem pressupô-la em seu sentido. Eles seriam categorias que expressam simplesmente sequências evolutivas de duração diversa, utilizadas com êxito na descrição de sistemas de relações que se manifestam no plano físico; porém, categorias inapropriadas para a compreensão das relações no plano da prática dos homens. Inversamente, os conceitos de passado, presente e futuro denotariam a relação estabelecida entre uma série de acontecimentos e a vivência que um indivíduo ou grupo tem dela (Elias, 1998b, p. 62-64).

Um determinado instante no interior de um fluxo contínuo só adquire um aspecto de presente em relação a um ser humano que o esteja vivendo, enquanto outros assumem um aspecto de passado ou de futuro. Em sua qualidade 
de simbolizações de períodos vividos, essas três expressões representam não apenas uma sucessão, como "ano" ou o par "causa-efeito", mas também a presença simultânea dessas três dimensões do tempo na experiência humana (Elias, 1998b, p. 63).

E, em seguida, Elias conclui que essas três palavras, "passado", "presente" e "futuro", embora diferentes, poderiam constituir-se num único e mesmo conceito - aproximando-se, ao menos nesse ponto, da interpretação do tempo de Santo Agostinho, que resume essas três dimensões temporais em presente das coisas passadas (lembrança), presente das presentes (visão) e presente das futuras (esperança) (Agostinho, 1984, p. 222). Isso se torna tanto mais patente quanto consideramos a reiterada ideia eliasiana acerca da capacidade humana de presentificação, ou seja, de experimentar como simultaneidade o não simultâneo.

218 Prosseguindo a sua argumentação, num segundo momento Elias relaciona os conceitos de passado, presente e futuro com as expressões temporais "mais cedo" e "mais tarde". Não obstante tanto estas como aqueles poderem se relacionar com as mesmas sequências de mudanças, ele advertiu que a simples classificação de um evento como "anterior" ou "posterior" independeria dos sujeitos de referência, já que, num único continuum evolutivo, o que ocorre "mais cedo" seria sempre anterior ao que ocorre "mais tarde" - a relação de ordem entre essas expressões seria fixa, sem qualquer referência a seres humanos determinados. Nesse ponto, evidentemente, Elias abstrai de sua argumentação as implicações da teoria da relatividade de Einstein, tanto no que diz respeito à irreversibilidade temporal quanto no que se refere ao caráter relativo - dependente do observador - atribuído por essa teoria ao conceito de simultaneidade e, portanto, às noções de anterioridade e posterioridade (Elias, 1998b, pp. 160-161). 
Em contrapartida, segundo nosso autor, os conceitos de passado, presente e futuro se ligariam às relações temporais que um grupo humano vivo estabeleceria entre uma série de mudanças qualquer - seja de ordem pessoal, social ou física - e o devir ao qual estaria submetido esse mesmo grupo. Tratar-se-iam, portanto, de conceitos temporais dependentes dos sujeitos de referência: um dado acontecimento é passado, presente ou futuro, sempre, para algum ser humano vivo determinado, considerado em seu devir. Ademais, tais conceitos teriam alguma significação mais clara apenas se considerados conjuntamente presentes na consciência dos homens (Elias, 1998b, pp. 64-65).

Após estabelecer tais distinções entre esses tipos de conceitos temporais, ${ }^{11}$ Elias apontou ainda uma diferença essencial entre as séries de fenômenos sociais e as outras séries alheias ao ser humano, constituídas por eventos puramente biológicos ou físicos. Naquelas, ao contrário destas, "a experiência vivida das sequências de acontecimentos é parte integrante, na ordem social, do próprio desenrolar dessas sequências". Donde ele conclui que os conceitos de passado, presente e futuro, em razão de seus vínculos diretos e exclusivos com tais vivências humanas, não seriam aplicáveis ao âmbito dos processos físicos, de modo que não haveria qualquer significado na divisão de sequências contínuas de eventos do mundo "natural" em sequências passadas, presentes e futuras. A não ser, advertiu Elias, que as sequências de eventos que se desenvolvem nesse âmbito guardem alguma relação de importância com a experiência vivida de seres humanos que remetem para si próprios esses eventos, numa espécie de identificação de cunho antropomórfico - é o caso de quando falamos do "futuro do Sol", por exemplo, para

\footnotetext{
11 Vale ressaltar que esses dois grupos de conceitos temporais correspondem às duas séries temporais analisadas pelo filósofo inglês John McTaggart (1866-1925) em sua célebre e controversa tese sobre a inexistência do tempo, publicada no início do século XX. Ver McTaggart (1988).
} 
nos referirmos a uma fase "futura" da sequência evolutiva de mudanças, de caráter sempre causal, a que está submetido esse tipo de estrela em nosso universo (Elias, 1998b, p. 65).

Mas os físicos falam normalmente de um passado ou de um futuro do universo. Segundo eles, na teoria de Newton, o passado existiria como uma série infinita de eventos, independente de qualquer observador. Dispondo de dados completos sobre o presente, as leis newtonianas - numa perspectiva determinista, apoiada no princípio de causalidade - permitiriam calcular um quadro integral do passado. Entretanto, segundo a maioria dos físicos teóricos contemporâneos, a física quântica teria alterado profundamente essa concepção, ao dizer-nos que, por mais detalhada que seja nossa observação do presente, o passado e o futuro seriam sempre indefinidos e apenas espectros de possibilidades. Desse modo, segundo a teoria quântica, o universo não teria um, mas infinitos passados e histórias; o passado de um sistema físico não teria uma 220 forma definida pois esse passado é afetado pelas observações desse sistema, feitas no presente. Esse princípio tem sido estendido ao âmbito da cosmologia, com a ideia de que o universo não teria uma história única independente do observador, mas diferentes histórias para diferentes estados possíveis no tempo presente: "criamos a história pela nossa observação, em vez de a história nos criar". Em suma, para a física newtoniana, existiria um passado, independente do observador; para a física quântica, infinitos passados, dependentes do observador (Hawking; Mlodinow, 2011, pp. 61-62 e 103).

Diante do exposto, talvez fosse o caso de ponderar a afirmação de Elias de que não haveria qualquer significado na divisão de sequências evolutivas de fenômenos físicos em sequências passadas, presentes e futuras - especialmente no caso de fenômenos físicos microscópicos. Essa afirmação é válida talvez menos em função dos vínculos diretos e exclusivos desses conceitos com as experiências humanas vividas, já que o ato de observar uma sequência evolutiva de fenômenos 
físicos poderia se constituir numa forma de experiência vivida, integrante dessa sequência, na medida em que o sujeito observador estaria afetando e moldando tanto o presente quanto o passado dessa própria sequência. Assim, tal afirmação é válida quiçá muito mais em virtude da relação de ordem causal - que conecta os eventos das sequências evolutivas de fenômenos físicos - não se encaixar nos conceitos de passado, presente e futuro, apesar de o caráter absoluto dessa ordem temporal sobre a qual se apoiam as relações causa-efeito dos processos físicos ser também uma questão já debatida contemporaneamente no campo da física quântica em investigações teóricas e empíricas em curso. Por outro lado, muito antes, o filósofo escocês David Hume (1711-1776) já havia questionado o fato da causalidade ser deduzida simplesmente da sucessão (Hume, 2001).

A propósito, o próprio Elias, ao tratar da relação entre dois acontecimentos sucessivos, destacou que, na experiência dos homens, o que ocorreu antes poderia ser colocado como causa do que ocorreu depois (consequências); porém, ao mesmo tempo, na experiência das gerações posteriores, o que ocorreu depois (consequências) teria uma repercussão sobre o sentido no qual o que ocorreu antes é "vivido" (Elias, 2001, p. 112) Ao contrário da ordem causal implícita na relação causa-efeito, tal como a vivenciamos na esfera do universo físico, nesse caso, surpreendentemente, se admitimos que o passado seja algo que de alguma maneira "antecede o futuro", essa ordem temporal poderia ser subvertida, no sentido de que o futuro, ou seja, "o que vem depois", pode "interferir no passado", ou melhor, na forma como esse passado é vivido. Por essa razão, as relações causais não se aplicam aos conceitos temporais de passado, presente e futuro. De qualquer modo, para Elias, teríamos duas espécies de conceitos temporais utilizados pelos seres humanos:

Por um lado, eles utilizam noções que remetem a sequências evolutivas que são objeto de uma apreensão 
consciente, sem dúvida, mas sem serem designadas como uma experiência deste ou daquele sujeito determinado na própria conceituação, e, por outro, utilizam noções como a maneira pela qual os seres humanos - que eventualmente fazem parte delas - vivem essas sequências na própria formação da conceituação (Elias, 1998b, p. 66).

Em suma, a distinção básica entre tais conceitos temporais estaria relacionada à inclusão ou não da experiência vivida no processo de conceituação. Embora reconhecendo a dificuldade de se construir uma tipologia adequada à diferenciação desses dois grupos de conceitos temporais, Elias acabou sugerindo o contraste entre conceitos "estruturais" e conceitos "ligados a uma experiência”. Embora fosse preciso, segundo ele, levar em conta as modificações no conceito de tempo ou nos conceitos temporais, decorrentes dos diferentes níveis atingidos no desenvolvimento das formações sociais, já que tais conceitos se

222 encontrariam continuamente em evolução. Ainda que tanto os conceitos estruturais quanto os experienciais representassem simbolicamente relações ou sínteses aprendidas, tais sínteses seriam de tipos diferentes. Apesar de ambos designarem o caráter anterior ou posterior dos eventos num continuum evolutivo, ao contrário dos outros conceitos temporais - como "mais cedo" e "mais tarde", por exemplo -, os conceitos de passado, presente e futuro constituiriam sínteses relativas a relações não causais entre tais eventos, ou, em outras palavras, eles formariam sínteses conceituais que incorporariam "certa maneira de viver as sequências de acontecimentos” (Elias, 1998b, p. 66, 115).

\section{A quinta dimensão simbólica da experiência ou consciência humana}

E aqui chegamos, finalmente, ao ponto culminante do esforço de elaboração e síntese teórica que Norbert Elias empreendeu a fim de oferecer uma abordagem que permitisse, segundo sua ótica, desfazer o aparente mistério acerca do caráter 
do tempo, gerado pela antítese filosófica entre subjetivismo e objetivismo, bem como pelas dicotomias dela decorrentes, intrínsecas às teorias tradicionais do conhecimento. Trata-se da sua ousada e complexa evocação de um universo de cinco dimensões. ${ }^{12}$ Com o surgimento da realidade especificamente humana, uma quinta dimensão viria a se somar - embora não numa mera justaposição - às quatro dimensões do universo físico, formadas pelo espaço e pelo tempo. Elias a denominou de dimensão da experiência vivida ou da consciência, ou ainda de símbolos socialmente aprendidos - como é o caso do tempo - que servem aos humanos como meios de comunicação, orientação e identificação (Elias, 1998b, pp. 66-67). Ao detalhar melhor essa imagem de um mundo de cinco dimensões, sobretudo em seu livro Teoria do símbolo, Elias procurou mostrar

o caráter duplo do mundo da nossa experiência, como um mundo independente de nós, mas que nos inclui, e como um mundo do qual nosso entendimento é intermediado por uma rede de representações simbólicas elaboradas pelo homem, predeterminadas por sua constituição natural, que se materializa apenas com a ajuda de processos sociais de aprendizagem, podendo chegar a ser mais ou menos congruente com a realidade. Podemos experienciar esse mundo e experienciar nós mesmos dentro dele no instante presente, de forma direta, como uma entidade tangível, como um momento em uma situação de mudança, hoje normalmente representada como um processo nas quatro dimensões espaçotemporais $^{13}$ (Elias, 1994c, p. 195, tradução nossa).

12 Elias demonstrou desde cedo um grande fascínio pelo tema mais geral das "dimensões" do universo e suas representações, o que certamente concorreu para a construção dessa alegoria pentadimensional, conforme se pode ver no relato de uma experiência de viagem a Florença, em 1925. Ver Elias (2001, p. 50).

13 “ $[. .$.$] el carácter doble del mundo de nuestra experiencia como un mundo$ independiente de nosotros pero que nos incluye y como un mundo del que hace de intermediaria para nuestro entendimiento una red de representaciones 
Consoante com tal perspectiva, o fato de que tudo que tem lugar no tempo e no espaço tenha também lugar na quinta dimensão não seria de modo algum inconciliável com o fato de que tudo que se situa na dimensão simbólica também se situa nas quatro dimensões formadas por tempo e espaço. E o tecido constituído pelos símbolos poderia muito bem ser concebido como outra dimensão, exatamente por abranger tudo o que existe, analogamente à trama espaço-temporal (Elias, 1994c, pp. 153-170).

Antes de prosseguir com a exposição e a interpretação da alegoria da quinta dimensão sugerida por Elias - e quem sabe para melhor compreendê-la -, talvez seja útil recorrer a uma analogia, de um lado - segundo Elias - entre o que o tempo representa na relação da quinta com a quarta dimensão e, de outro - de acordo com os físicos -, o que ele significa na relação da quarta com a terceira dimensão de nosso universo físico. Pelas teorias da relatividade, de Einstein, e do eletro224 magnetismo, de Maxwell, o tempo não poderia ser tratado separadamente das três dimensões do espaço, sendo necessário juntar a elas uma dimensão temporal, formando assim uma unidade, o espaço-tempo, que os físicos convencionaram chamar de quarta dimensão. Uma nomenclatura que pode se prestar a equívocos, pois, na verdade, o tempo não representa nela mais uma dimensão separada das três espaciais. Em lugar de uma justaposição, há uma interconexão essencial, mediante uma espécie de onipresença do tempo nas dimensões espaciais (Hawking; Mlodinow, 2011, p. 74).

$\mathrm{O}$ que Elias pretendeu destacar com seu modelo foi precisamente essa interconexão entre as cinco dimensões, de modo

simbólicas hechas por el hombre, predeterminadas por su constitución natural, que sólo se materializa con ayuda de procesos de aprendizaje social. Puede llegar a ser más congruente con la realidad y menos. Podemos experimentar este mundo y experimentamos a nosotros mismos dentro de él en el instante presente directamente como una entidad tangible, como un momento en una situación de cambio normalmente representada hoy como un proceso en las cuatro dimensiones de tiempo y espacio" (Elias, 1994c, p. 195). 
que o tempo seria algo integrante, sem qualquer contradição, tanto do universo pentadimensional quanto do universo quadridimensional. Assim, o que chamamos tempo designaria uma das dimensões constitutivas do universo físico quadridimensional, que representa a totalidade do mundo perceptível, no sentido de que "tudo o que é perceptível, inclusive a realidade humana, ocupa uma posição em cada uma das quatro dimensões formadas pelo espaço e pelo tempo". Contudo, paralelamente, o tempo seria também um símbolo social e, enquanto tal, um "representante do mundo humano de cinco dimensões". Diante dessa "estranha vida dupla do tempo", Elias formulou as seguintes perguntas: qual seria a relação recíproca entre essas duas determinações do tempo? Seriam elas conciliáveis? (Elias, 1998b, p. 31). O nosso autor daria início ao esforço de responder essas questões afirmando que

existem acontecimentos que podem ser percebidos como tais no fluxo do devir, e portanto, no tempo e no espaço, sem que aqueles que os percebem levem em consideração o caráter de símbolos do tempo e do espaço. Nesse caso, não levamos em conta, por não nos apercebermos dele, o fato de que uma atividade humana ordenadora, uma síntese consciente aprendida, é necessária para que os processos perceptíveis sejam captados como algo situado no espaço e no tempo (Elias, 1998b, p. 31).

Em outras palavras, os seres humanos, ao perceberem certos fatos situados nas dimensões espaço-temporais, nem sempre seriam conscientes do caráter simbólico do tempo e do espaço, pois não se dão conta de que, para tanto, seria necessária "uma atividade humana ordenadora", "uma síntese consciente aprendida". Daí decorre que, ao observar e perceber um universo quadridimensional, num primeiro momento os homens ainda não se incluiriam a si próprios como sujeitos da observação e da percepção. Assim, prossegue Elias, estariam 
dadas as condições para se alçar um patamar na escala da consciência. Com a introdução de uma quinta dimensão no campo de visão dos observadores - representada pelos homens que ordenam e apreendem os acontecimentos percebidos no tempo e no espaço - estes passariam a ver a si próprios no nível imediatamente abaixo dessa escala. Mediante tal "distanciamento" e dotados de uma espécie de "lentes pentadimensionais", esses observadores passariam a enxergar não apenas o devir quadridimensional como tal, mas também o caráter simbólico das quatro dimensões, na sua função de instrumentos de orientação humana no seio do fluxo incessante do devir. Ou seja, a especificidade simbólica das quatro dimensões se manifestaria quando ascendêssemos a um patamar superior do saber e a humanidade passasse a ser incluída, como sujeito, nesse mesmo saber (Elias, 1998b, pp. 31-32). Assim, Elias concluiria sua resposta às perguntas formuladas anteriormente, sobre a natureza dual do tempo - pertencente simultanea226 mente à quarta e à quinta dimensão-, dizendo que

O tempo, que só era apreendido, no patamar anterior, como uma dimensão do universo físico, passa a ser apreendido, a partir do momento em que a sociedade se integra como sujeito do saber no campo da observação, como um símbolo de origem humana e, ainda por cima, sumamente adequado a seu objeto (Elias, 1998b, p. 31).

Como os conceitos temporais "experienciais" do tipo passado, presente e futuro se caracterizariam precisamente por estruturar "a experiência do devir em função de sua relação com o continuum evolutivo representado pelos grupos humanos que vivem essa experiência”, conclui-se que tais conceitos integrariam efetivamente essa quinta dimensão simbólica, formada por tempo, espaço, linguagem, pensamento, conhecimento, memória, consciência etc. (Elias, 1998b, p. 66). 
A despeito de Elias denominar essa quinta dimensão simbólica de dimensão da experiência vivida ou da consciência, ele não explicita em sua obra o significado de tais conceitos de forma detalhada. Deduz-se, no primeiro caso, que não se trata de uma experiência qualquer, mas de uma experiência vivida e, enquanto tal, de uma experiência viva, uma vivência. Poderíamos dizer, de forma geral, que tal conceito remete à ideia da vida experimentada, lembrada e, portanto, à consciência que se toma e que se conserva da vida. Nesse sentido, poderia designar certa expressão da consciência - como um pensamento que se pensa reflexivamente, uma ciência de si junto a uma ciência de algo (Comte-Sponville, 2011, pp. 122-123, 634).

Praticamente tudo o que foi aqui dito a respeito da essência do tempo se aplicaria igualmente ao espaço, enquanto dimensão do universo físico e, simultaneamente, símbolo social forjado pela humanidade. O que o espaço é para a extensão o tempo é para a duração. Tempo e espaço representariam ambos uma síntese conceitual de alto nível, relações de ordem puramente posicional entre acontecimentos observáveis. A diferença é que, enquanto o tempo remeteria a relações posicionais determinadas no interior de um fluxo, considerando seus deslocamentos e mudanças contínuas, o espaço remeteria a relações posicionais entre acontecimentos móveis com a abstração de seus movimentos e mudanças efetivas. Mas essas relações posicionais seriam absolutamente inseparáveis umas das outras, de modo que toda mudança no tempo seria uma mudança no espaço e vice-versa. Por considerar tão evidente essa unidade, Elias dispensou, nesse ponto, a evocação da própria história da unificação conceitual do tempo e do espaço no âmbito das teorias científicas, que teria culminado, em Minkowski ${ }^{14}$ e Einstein, no conceito

14 Hermann Minkowski (1864-1909), matemático alemão que contribuiu sobremaneira para a divulgação da teoria da relatividade de Einstein - a propósito, seu ex-aluno em Zurique -, ao propor, em 1908, a compreensão dessa teoria a partir da introdução do conceito de "espaço-tempo" como uma unidade de quatro dimensões. 
de uma única unidade espaço-tempo, enquanto um contínuo quadridimensional ${ }^{15}$ (Elias, 1998b, pp. 80-82).

Por fim, essa imagem da quinta dimensão simbólica experiencial evocada por Elias revelou não apenas a essência do seu conceito de tempo - e de espaço - como um símbolo social, mas, sobretudo, seu esforço de oferecer uma alternativa às conceituações antitéticas e dicotômicas que tendiam a dividir o tempo em objetivo e subjetivo, físico e social etc. Elias lamentou não apenas a carência e insuficiência de pesquisas sobre essa dimensão "experiencial" do real ou sobre o "tempo vivido" - dimensão propriamente humana e social - mas, principalmente, o fato de tais estudos ficarem facilmente entregues à esfera da especulação ou da metafísica, apontando como exemplo as abordagens de Bergson e Heidegger (Elias, 1998b, pp. 68-69). Em seu livro Envolvimento e alienação, de 1983, ao reiterar seu compromisso com os estudos dessa dimensão, ele afirmou que 228 a sua sociologia configuracional se centraria exatamente sobre "uma imagem pentadimensional da pluralidade dos seres humanos que inclui os aspectos comportamentais quadridimensionais diretamente visíveis e o 'vivencial'..." (Elias, 1998a, p. 264).

\section{Considerações finais}

Com a imagem das cinco dimensões, Norbert Elias conseguiu construir e oferecer uma alternativa criativa às abordagens do tempo oferecidas pelas filosofias ou epistemologias tradicionais, que alimentavam - e talvez sigam alimentando, ainda que em menor medida - a controvérsia acerca do caráter objetivo ou subjetivo do tempo.

\footnotetext{
15 As descobertas transcendentais de Einstein sobre a natureza do espaço-tempo não implicam, todavia, que antes dele ninguém tivesse se dado conta de que não é possível situar um acontecimento no espaço sem situá-lo juntamente no tempo. $\mathrm{O}$ valor de Einstein, segundo Elias, foi ter demonstrado e expressado isso cientificamente. Ver, a propósito, Elias (1994c, p. 34).
} 
Abordagens essas que, segundo Elias, tendiam a conceber o mundo a partir de uma infinitude de antíteses não processuais, sendo responsáveis pelas cisões entre objeto e sujeito, natureza e sociedade, mundo físico e mundo social e, consequentemente, entre tempo físico e tempo social, tomados como existencialmente independentes e inconciliáveis.

O esforço teórico de Elias se concentrou em elaborar uma síntese complementar e processual para o problema do tempo, que conectasse numa unidade esses pares dicotômicos, não apenas como uma mera soma, mas como uma articulação necessária. Sua ideia de uma quinta dimensão simbólica romperia, assim, com o antagonismo entre tempo físico e tempo social e tantos outros que o acompanham, exatamente por considerar que a dimensão simbólica não é incompatível com a dimensão do universo físico, havendo uma interligação entre elas. Assim, tempo físico e tempo social seriam apenas exemplos das múltiplas noções em que o conceito de tempo se dividiu, em antíteses, em partes justapostas, sem qualquer nível de articulação. O tempo simbólico, integrante da quinta dimensão da consciência, da experiência, constituiria tal síntese.

Nesse sentido, não obstante sua abordagem ter desconsiderado certos aspectos essenciais proporcionados pelos avanços mais recentes nos campos da física relativística e da física quântica - notadamente no que diz respeito à influência e ao papel do observador na determinação do tempo -, a conceituação do tempo de Elias pode ser considerada uma alternativa instigante e, em certa medida, original, frente aos esquemas objetivistas e subjetivistas da gnosiologia tradicional. Sua abordagem pode ter contribuição frutífera para o entendimento e elucidação do problema filosófico do tempo, na medida em que permite esclarecer - ainda que parcialmente - certos aspectos do enigma que envolve esse termo, colaborando 
assim - como expressado pelo próprio Elias - com a compreensão da condição humana.

Daí que sua crítica à dicotomia entre tempo físico e tempo social, mais do que uma reflexão sobre o tempo, pode fornecer um subsídio importante para o debate tanto no âmbito da problemática epistemológica - das complexas relações entre objeto e sujeito, entre natureza e sociedade e, consequentemente, entre as ciências físico-naturais e as ciências humanas e sociais - quanto na esfera da linguagem - do melhor conhecimento das funções dos símbolos sociais, como é o caso do tempo, como meios de comunicação e orientação humana. Sem contar ainda sua fértil contribuição para a reflexão acerca da essência e das relações entre os diferentes conceitos temporais, que pode abrir possibilidades úteis para se pensar outras noções temporais - como a de tempo histórico - enquanto parte de uma investigação sobre as articulações entre as várias noções em que o conceito mais geral de tempo se fragmentou.

Por fim, se a formação do universo pentadimensional, de acordo com a elaboração conceitual de Elias, teria marcado o início da aventura especificamente humana, a quinta dimensão eliasiana poderia representar, parafraseando Machado de Assis, o tecido invisível onde se borda tudo o que é exclusivamente humano: uma linguagem, um pensamento, um conhecimento, uma consciência, uma experiência vivida, um símbolo de espaço e um símbolo de tempo. Em suma, um tecido sem bordas no qual, além dos conceitos de uma flor, um pássaro, uma dama, um castelo ou um túmulo, se poderia bordar um conceito de tecido, um conceito de invisível e, até mesmo, um conceito de nada.

\section{Eugênio Rezende de Carvalho}

é Professor Titular da Faculdade de História da Universidade Federal de Goiás. Goiânia, GO, Brasil. 


\section{Bibliografia}

AGOSTINHO, Santo. 1984. Confissões. In: . Santo Agostinho. São Paulo:

Abril Cultural.

CASSIRER, Ernst. 1994. Ensaio sobre o homem: introdução a uma filosofia da cultura humana. São Paulo: Martins Fontes. . 2001. Filosofia das formas simbólicas I: a linguagem. São Paulo:

Martins Fontes.

2004. Filosofia das formas simbólicas II: o pensamento mítico. São Paulo: Martins Fontes.

. 2011. Filosofia das formas simbólicas III: fenomenologia do conhecimento. São Paulo: Martins Fontes.

COMTE-SPONVILLE, André. 2011. Dicionário filosófico. São Paulo: Martins Fontes.

ECO, Umberto. 1991. Semiótica e filosofia da linguagem. São Paulo: Ática.

ELIAS, Norbert. 1991. The symbol theory. London: Sage. . 1993. O processo civilizador: formação do Estado e civilização. Vol. 2.

Rio de Janeiro: Jorge Zahar. . 1994a. A sociedade dos indivíduos. Rio de Janeiro: Jorge Zahar. . 1994b. Reflections on a life. Cambridge: Blackwell Publishers;

Malden: Polity Press. 1994c. Teoría del símbolo: un ensayo de antropología cultural.

Barcelona: Península. . 1998a. Envolvimento e alienação. Rio de Janeiro: Bertrand Brasil. . 1998b. Sobre o tempo. Rio de Janeiro: Jorge Zahar. 2001. Norbert Elias por ele mesmo. Rio de Janeiro: Jorge Zahar. 2008. Introdução à sociologia. Lisboa: Edições 70.

2011. O processo civilizador: uma história dos costumes. Vol. 1. Rio de Janeiro: Jorge Zahar.

ELIAS, Norbert; DUNNING, Eric. 1992. A busca da excitação. Lisboa: Difel. ESPINOSA, Baruch de. 1983. Pensamentos metafísicos. In:

Espinosa. São Paulo: Abril Cultural.

HAWKING, Stephen; MLODINOW, Leonard. 2011. O grande projeto: novas respostas para as questões definitivas da vida. Rio de Janeiro: Nova Fronteira. HUME, David. 2001. Tratado da natureza humana. São Paulo: Unesp; Imprensa Oficial.

LEIBNIZ, Gottfried Wilhelm. 1983. Correspondência com Clarke. In: NEWTON, Isaac; LEIBNIZ, Gottfried Wilhelm. Newton Leibniz. São Paulo: Abril Cultural.

MCTAGGART, J. 1988. The nature of existence. Cambridge: Cambridge University Press. 


\section{A CONCEPÇÃO HOLÍSTICA E PROCESSUAL DE TEMPO DE NORBERT ELIAS}

\section{EUGÊNIO REZENDE DE CARVALHO}

Resumo: O sociólogo alemão Norbert Elias (1897-1990), em suas reflexões sobre o tempo, definiu-o como um símbolo social e relacional, integrante de uma quinta dimensão simbólica, a da experiência, ou consciência humana. Tal imagem eliasiana de um universo pentadimensional se apoiou no reconhecimento da interdependência e imbricação mútua entre os níveis físico, biológico, social e individual, sem o qual - para esse autor - o enigma que envolve o conceito de tempo continuaria sem solução. Assim, Elias propôs uma síntese, de caráter processual, que conectasse numa unidade os pares dicotômicos que tradicionalmente tinham - e ainda têm - permeado as abordagens filosóficas sobre o tempo: tempo objetivo e subjetivo, tempo da natureza e da consciência, tempo físico e social, tempo cosmológico e fenomenológico etc. Este texto explora criticamente os fundamentos da concepção eliasiana do tempo, em sua abordagem holística e processual, bem como alguns de seus possíveis desdobramentos na compreensão desse conceito pelas diversas áreas do conhecimento.

Palavras-chave: Norbert Elias; Tempo; Conceitos Temporais; Tempo Simbólico; Tempo Relacional.

\section{NORBERT ELIAS' HOLISTIC AND PROCEDURAL CONCEPTION OF TIME}

Abstract: The German sociologist Norbert Elias (1897-1990) defined time as a social and relational symbol, belonging to a fifth symbolic dimension, the human experience or consciousness. This eliasian image of a five-dimensional Universe is based on the understanding of the interdependency and mutual overlap 
among the physical, biological, social, and individual levels of integration, without which, the enigma surrounding the concept of time would remain without a solution for this author. Thus, Elias proposed a procedural synthesis that connects as a unit the dichotomous pairs that traditionally - and still - permeate the philosophical approaches about time: subjective and objective time, time of nature and time of consciousness, physical and social time, phenomenological and cosmological time, etc. This article critically examines the foundations of the eliasian idea of time in its holistic and procedural approach, as well as some of the possible outcomes in the understanding of this concept by different areas of knowledge.

Keywords: Norbert Elias; Time; Time Concepts; Symbolic Time; Relational Time.

Recebido: 08/06/2016 Aprovado: 23/03/2018 